\title{
Experimental evaluation of phase change material in radiant cooling panels integrated with thermoelectric modules
}

\author{
Yong-Kwon Kang ${ }^{1}$, Beom-Jun $\mathrm{Kim}^{1}$, Soo-Yeol Yoon ${ }^{1}$, and Jae-Weon Jeong ${ }^{1,}$ * \\ ${ }^{1}$ Department of Architectural Engineering, Hanyang University, Republic of Korea
}

\begin{abstract}
This study proposes a phase change material for use in radiant cooling panels integrated with thermoelectric modules (PCM-TERCP) and evaluates its performance characteristics during the solidification and melting process of phase change materials in design conditions. The PCM-TERCP consists of phase change materials (PCMs), thermoelectric modules (TEMs), and aluminum panels. TEMs operate to freeze the PCM, and PCM stores the cooling thermal energy to maintain the constant surface temperature of the panel for radiant cooling. The main purpose of thermal energy storage systems is the shift of the electricity consumption from day-time to night-time during the summer season. Therefore, PCM-TERCP can implement off-peak operation according to which energy is expected to be saved. The melting temperature of PCM and the target surface temperatures of the bottom panels of PCM-TERCP were designed to be $16^{\circ} \mathrm{C}$. Additionally, the room temperature and mean radiant temperature (MRT) was set to $24^{\circ} \mathrm{C}$, while the thickness of the PCM pouch was $10 \mathrm{~mm}$. As a result, the solidification process required $4 \mathrm{~h}$ and the total input power was 0.528 $\mathrm{kWh}$. Correspondingly, the melting process can operate passively over a period of $4 \mathrm{~h}$. In most cases, the operating temperature was lower than $19^{\circ} \mathrm{C}$, which validates the temperature response of PCM-TERCP.
\end{abstract}

\section{Introduction}

According to some published studies, energy consumption in buildings accounts for almost $41 \%$ of the world's energy consumption [1]. Most of this energy consumption occurs in heating, ventilation, and air conditioning (HVAC). Accordingly, to decrease the HVAC energy consumption, many decoupling systems that effectively decouple the sensible and latent loads have been studied and used. Among the sensible cooling units, ceiling radiant cooling panels (CRCPs) have been used because they are quiet, efficient, and can supply better thermal comfort than other parallel cooling units [2]. However, CRCPs use the chilled water from the vapor compression cooling system. Therefore, many researchers studied the non-vapor compression technique without a refrigerant to replace the vapor compression system.

The thermoelectric module (TEM) is a solid-state heat pump that operates based on the Peltier effect. The TEM can operate without refrigerants, moving parts, or noise, and has a compact size. Although the TEM has a low Coefficient of performance (COP), it has attracted increased attention as a substitute technology for refrigerant heat pumps. The water-cooled-type TEM radiant cooling panel (TERCP) with a DOAS system can save approximately $44.5 \%$ of energy compared to conventional variable air volume systems (VAVs) [3]. However, the low-COP of the TEM still causes considerable energy consumption. Therefore, to increase the utilization of TEM, we integrated it with the thermal storage material.
Phase change materials (PCM) are one of the types of thermal storage materials that can store a large amount of energy in the form of latent heat with small temperature changes. This property allows the PCM to be applied to the radiant cooling or heating systems. Recently, many studies have been conducted using phase change materials for radiant heating $[4,5]$. Compared with the PCM floor heating and general floor heating (using hot water), the outcomes of these studies showed that the PCM floor heating can maintain room temperatures at approximately $1.5^{\circ} \mathrm{C}$ higher than those of the general floor heating room temperature [6]. However, to-this-date only limited studies have been conducted in terms of the PCM radiant cooling system. Consequently, this study proposes the phase change material used in ceiling radiant cooling panels with thermoelectric modules (PCM-TERCP) and evaluates its performance characteristics during the solidification and melting processes of the phase change materials in design condition.

\section{System overview}

As shown in Figure 1, a thermoelectric module radiant cooling panel integrated with phase change material (PCM-TERCP) was installed at the ceiling of the zone like other ceiling radiant cooling panels and removed the sensible cooling load of the zone.

There are two operating modes for PCM-TERCP. The first is the solidification mode. When PCM-TERCP operates according to this mode (Figure 1(a)), the thermoelectric modules (TEM) operate based on the

\footnotetext{
* Corresponding author: ijwarc@hanyang.ac.kr
} 
Peltier effect at night time. When all the PCM is solidified, TEMs are shut down. A fan operates to remove unnecessary heat to the outdoors through the heat sink. The second mode is the melting mode. When PCMTERCP operates as the melting mode (Figure 1(b)), the solidified PCM maintains the temperature of the bottom aluminum panel to remove the cooling load of the conditioned zone. During this time, the fan and TEMs are not operational.

As shown in Figure 2, the mock-up model of the PCM-TERCP consists of three layers. The first layer is consisted of the thermoelectric modules (TEMs), aluminum panel, and heat sinks and it is the same as the thermoelectric module radiant cooling panel (TERCP) used in a previous study [7]. The cold side of the TEMs was attached to the top aluminum panel, and the hot side was attached to the heat sink. The latter consisted of heat pipes and fins and dissipated the heat to the outdoor air to maintain the performance of the TEMs. The thickness of the top aluminum panel was $5 \mathrm{~mm}$ to prevent bending stress. The second layer was the PCM pouch. The pouch was made of coated aluminum film. Two PCM pouches were installed between the top and bottom aluminum panels and prevented damage to PCM pouches. Their sizes were $0.38 \mathrm{~m}$ (width) $\times 0.17 \mathrm{~m}$ (length) $\times 0.01 \mathrm{~m}$ (height). The last layer was the bottom aluminum panel, which had a thickness of $3 \mathrm{~mm}$ for structural safety.

To prevent the unnecessary heat transfer, the compressed polystyrene foam was attached around the plenum. Additionally, the Teflon insulations were attached between the top aluminum panel and the air plenum.

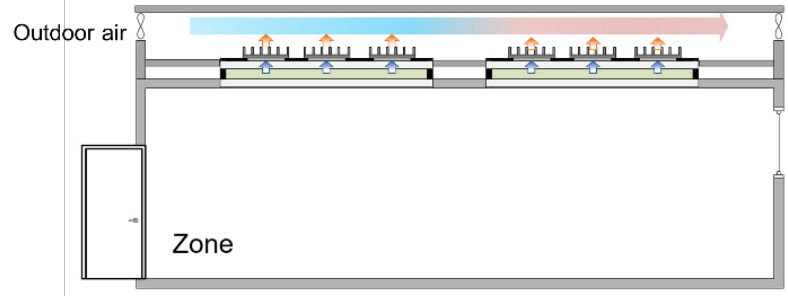

(a) Solidification mode

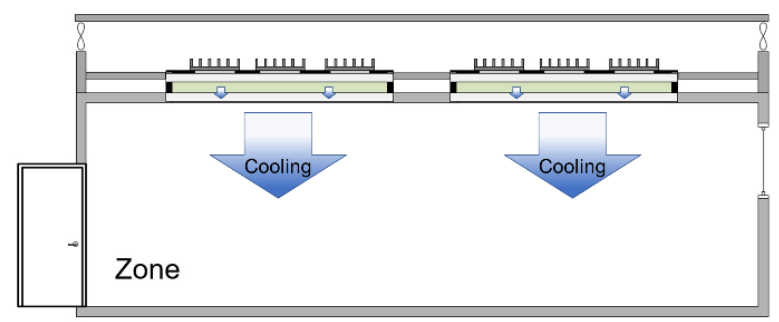

(b) Melting mode

Fig. 1. Schematics of the PCM-TERCP in the (a) solidification and (b) melting mode zones.

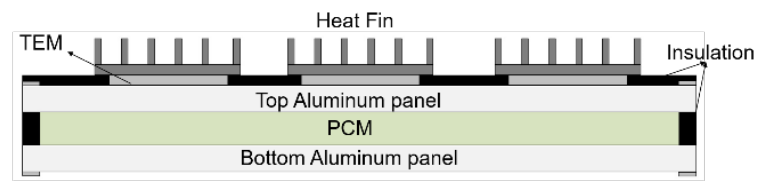

Fig. 2. Section diagram of the PCM-TERCP.
As shown in Figure 3, the plenum size was $0.4 \mathrm{~m}$ (width) $\times 0.4 \mathrm{~m}$ (length) $\times 0.2 \mathrm{~m}$ (height), and the bottom aluminum panel size used for the experiments was $0.4 \mathrm{~m}$ (width) $\times 0.4 \mathrm{~m}$ (length) $\times 0.003 \mathrm{~m}$ (height). As shown in Figure 4 , the PCM-TERCP installed three TEMs in a triangular grid with a $0.28 \mathrm{~m}$ spacing between TEMs [7], based on the previous study.
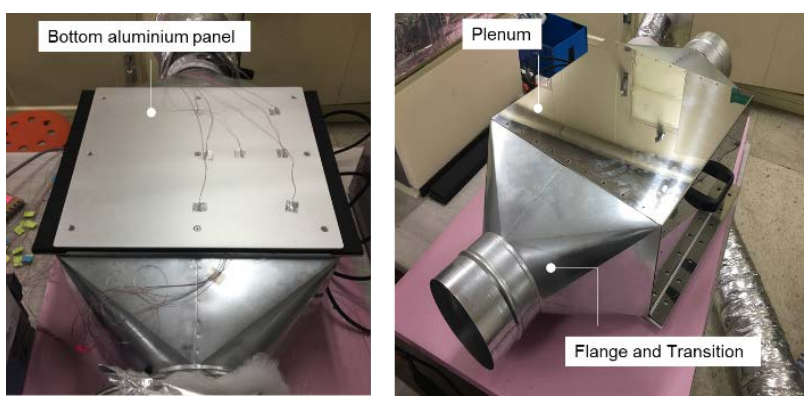

Fig. 3. Exterior part of the PCM-TERCP mock-up model.
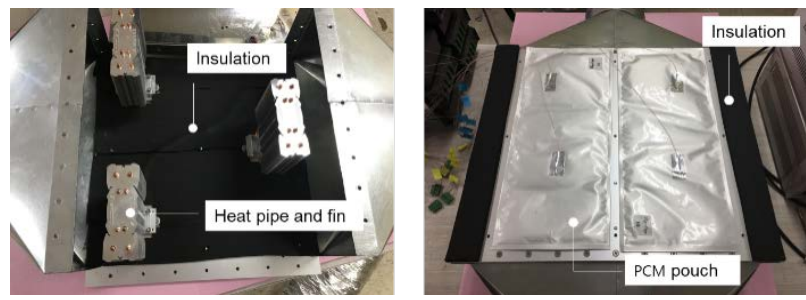

Fig. 4. Interior part of the PCM-TERCP mock up model.

\section{Experimental setup}

The experiments were conducted using the setup shown in Figure 5 to analyze the performance of the PCMTERCP. When the PCM-TERCP operated in the solidification mode, the environmental chamber, switched \pm mode power supply (SMPS), constant temperature plate, PCM-TERCP, and a data logger were used. In the melting mode, a data logger, constant temperature plate, and the PCM-TERCP were used. Technical specifications of the TEMs are shown in Table 1.

The surface temperatures of the PCM-TERCP were measured using thermocouples and the YOKOGAWA MV2000 data logger. Twenty-eight thermocouples (OMEGA, T type: measuring efficiency $\pm 0.5^{\circ} \mathrm{C}$ ) were used in total to measure surface temperatures with the use of seven thermocouples attached on each surface (Figure 6 (a)). There are four points in the vertical direction for the measurements of the top surface of the panel, top surface of PCM, bottom surface of the panel, and the bottom surface of the PCM (Figure 6 (b)).

Direct current (DC) power was applied to the TEMs by using the SMPS. The power was distributed through the terminal box to the TEMs.

The constant temperature plate was used to emulate the room temperature of the conditioned zone. The constant temperature plate controller maintained the surface temperature of the constant temperature plate through the use of proportional integral derivative (PID) control. In the experiments, the room condition was 
emulated using a constant temperature plate based on the combined indoor heat transfer coefficients (i.e., convection and radiation coefficients) estimated using theoretical calculations. When the constant temperature plate maintained the constant surface temperature that was equal to the room temperature, the insulation was installed between the radiant cooling panel and the constant temperature plate. The combined heat transfer coefficient of the insulation should be matched to the calculated heat transfer coefficient to emulate the room conditions for the radiant cooling panel. The calculated, combined heat transfer coefficient was $9.5 \mathrm{~W} / \mathrm{m}^{2} \mathrm{~K}$ in natural convection conditions. In addition, the heat conductivity of the insulation was $0.032 \mathrm{~W} / \mathrm{m} \cdot \mathrm{K}$. Therefore, the thickness of the insulation was approximately $5 \mathrm{~mm}$ when the heat transfer area was 0.16 $\mathrm{m}^{2}$ [8]. For the execution of the experiments, the room air temperature was set to $24^{\circ} \mathrm{C}$, which was a comfortable indoor temperature in the summer season, as presented in the ASHRAE standard [9]. In addition, the mean radiant temperature (MRT) was assumed to be the same as the room air temperature in all experiments. This mock-up model applied the air-cooled type system and used the environmental chamber to emulate the outdoor air temperature.

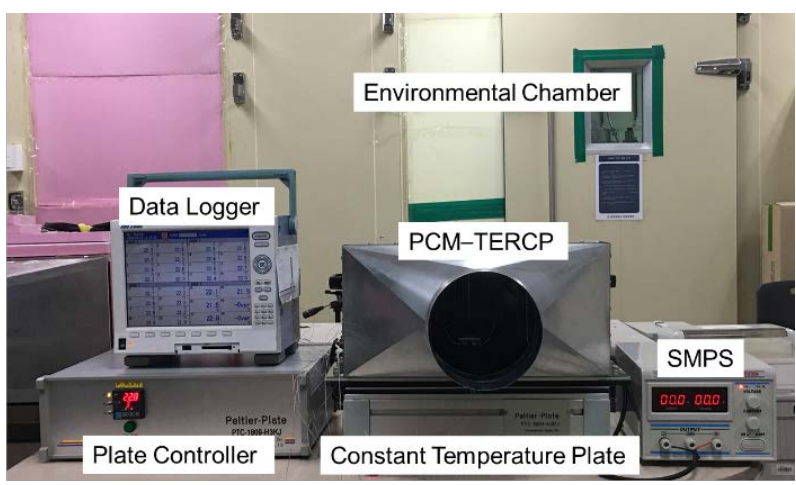

Fig. 5. Schematic diagram of the experimental setup of the PCM-TERCP.

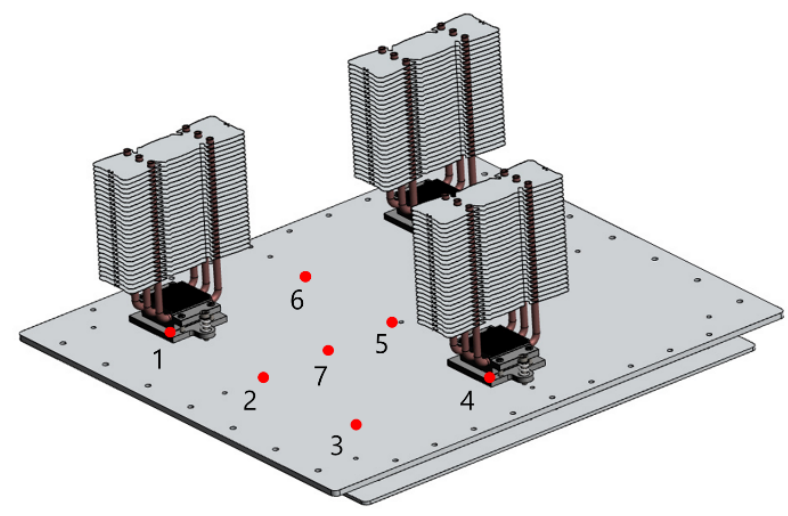

(a) Thermocouple measurement locations on the floor plan

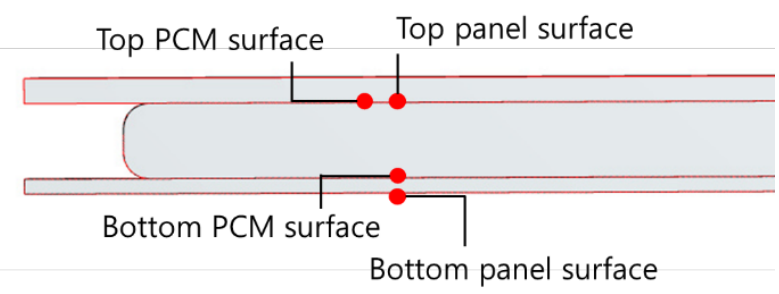

(b) Thermocouple measurement locations shown in the floor plan's cross-section

Fig. 6. Schematic of the thermocouple locations at the PCMTERCP.

The PCM used in this experiment was n-Alkane, its melting point was $16^{\circ} \mathrm{C}$, and its latent heat was $200 \mathrm{~kJ} / \mathrm{kg}$ (Table 2). The reason for choosing the melting point at $16^{\circ} \mathrm{C}$ is that the general surface temperature of the radiant cooling panel was $16^{\circ} \mathrm{C}$ to prevent condensation problems [10].

Table 1. Technical specifications of TEM in PCM-TERCP

\begin{tabular}{|c|c|}
\hline Description & Value \\
\hline Dimension & $40 \mathrm{~mm} \times 40 \mathrm{~mm} \times 3.8 \mathrm{~mm}$ \\
\hline $\mathrm{I}_{\max }$ & $6.4 \mathrm{~A}$ \\
\hline $\mathrm{V}_{\max }$ & $14.7 \mathrm{~V}$ \\
\hline $\mathrm{Q}_{\max }$ & $56 \mathrm{~W}$ \\
\hline$\Delta \mathrm{T}_{\max }$ & $71^{\circ} \mathrm{C}$ \\
\hline
\end{tabular}

Table 2. Technical specifications of the PCM pouch

\begin{tabular}{|c|c|}
\hline Description & Value \\
\hline Dimension & $38 \mathrm{~mm} \times 17 \mathrm{~mm} \times 1 \mathrm{~mm}$ \\
\hline Phase change temperature & $16^{\circ} \mathrm{C}$ \\
\hline Latent heat of capacity & $200 \mathrm{~kJ} / \mathrm{kg}$ \\
\hline Specific heat of capacity & $2 \mathrm{~kJ} / \mathrm{kg}$ \\
\hline Density & $770 \mathrm{~kg} / \mathrm{m}^{3}$ \\
\hline Thermal conductivity & $0.2 \mathrm{~W} / \mathrm{m} \cdot \mathrm{K}$ \\
\hline
\end{tabular}

\section{Experimental results}

In the solidification process, the average temperature of the bottom side of the PCM was lower than the melting point of $3^{\circ} \mathrm{C}$. Accordingly, it was considered that the PCM was frozen. The input current and voltage were $11 \mathrm{~A}$ and $12 \mathrm{~V}$. As shown in Figure 7, the solidification process was conducted for four hours. The total input power of the PCM-TERCP was $528 \mathrm{Wh}$.

During the melting process, the average surface temperature of the aluminum panel at the bottom side was higher than the melting point of $3^{\circ} \mathrm{C}$. Accordingly, it was considered that the PCM-TERCP has no more cooling capacity. After four hours, the average surface temperature of the aluminum panel at the bottom side increased up to $19^{\circ} \mathrm{C}$. It was confirmed that the PCM- 
TERCP in the passive cooling mode operated at a temperature which was equal to the difference of the mean temperature of the bottom surface and the room temperature which was in the range of $5^{\circ} \mathrm{C}$ to $8^{\circ} \mathrm{C}$.

As shown in Figure 8, during the melting process, PCM-TERCP elicited a temperature difference between the maximum and minimum temperatures at the bottom aluminum panel which was within $1^{\circ} \mathrm{C}$. This value was smaller than the $3{ }^{\circ} \mathrm{C}$ criteria recommended by the ASHRAE standard.

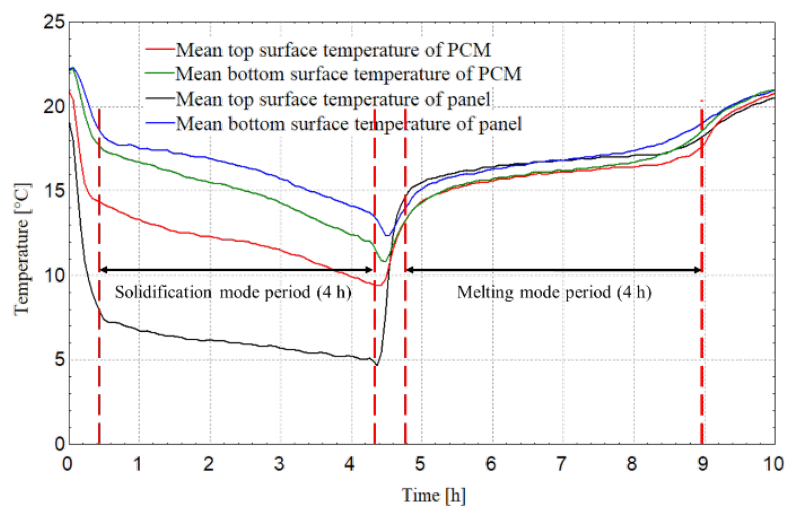

Fig. 7. Mean surface temperature variations of PCM-TERCP during the solidification and melting processes.

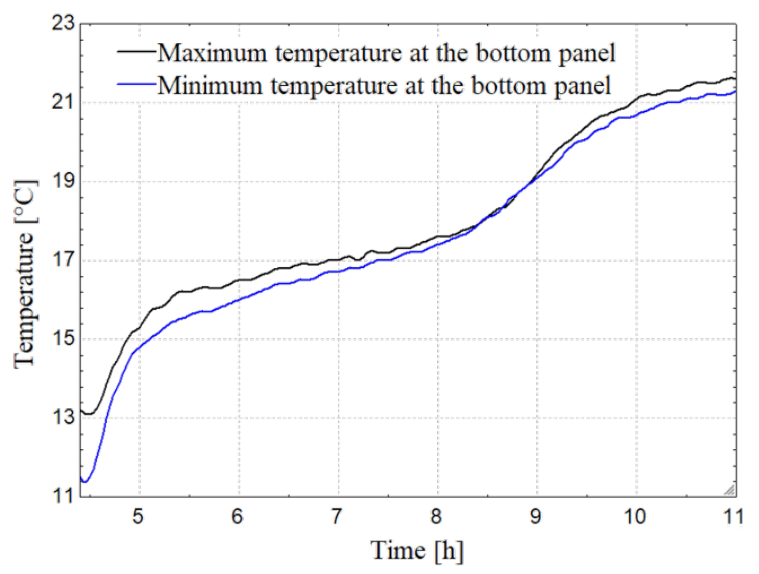

Fig. 8. Maximum and minimum temperatures at the bottom panel of PCM-TERCP.

\section{Conclusions}

This study proposed the use of PCM-TERCP and analyzed its characteristic in the solidification and melting processes. A mock-up model of PCM-TERCP was constructed for experiments and the room temperature and MRT were emulated using the constant temperature plate, while the combined heat transfer coefficient of the conditioned zone was emulated using insulations. As a result, the solidification process required $4 \mathrm{~h}$ and the total input power was $528 \mathrm{Wh}$. Additionally, the melting process was operated passively during a $4 \mathrm{~h}$ period. During most of the time, the operation temperature was maintained at values lower than $19^{\circ} \mathrm{C}$. Therefore, the PCM-TERCP elicited a good surface temperature for radiant cooling. In the future, a follow-up project will quantify the performance and energy consumption of the PCM-TERCP at different thickness values of the PCM pouch, indoor, and outdoor conditions.

This work was supported by the Korean Agency for Infrastructure Technology Advancement (KAIA) grants (19CTAP-C141826-02), and by the Korean Institute of Energy Technology Evaluation and Planning (KETEP) (No. 20184010201710)

\section{References}

1. C. Initiative, Buildings and Climate Change, (2009)

2. J.W. Jeong, S.A. Mumma, W.P. Bahnfleth, ASHRAE Transactions 109 Part 2, 627-636 (2003)

3. H.S. Lim, J.W. Jeong, Energy and Buildings, 169, 353-365 (2018)

4. R. Ansuini, R. Larghetti, A. Giretti, M. Lemma, Energy and Buildings, 43, 3019-3026 (2011)

5. S. Sattari, B. Farhaneh, Renewable Energy, 31, 1617-1626 (2006)

6. T.W. Kim, Y.K Yang, M.Y. Kim, J.C. Park, SAREK 18-S-014, 49-52 (2018)

7. H.S. Lim, Y.K. Kang, J.W. Jeong, Journal of Energy Engineering, 144, 248-261 (2018)

8. M. Koschenz, B. Lehmann, Energy and Buildings, 36, 567-578 (2004)

9. American Society of Heating Refrigerating and AirConditioning Engineers (ASHRAE), ASHRAE STANDARAD: Thermal Environmental Conditions for Human Occupancy (2013)

10. American Society of Heating Refrigerating and AirConditioning Engineers (ASHRAE), ASHRAE Handbook-HVAC: Systems and Equipment, Chapter 6: Radiant heating and cooling (2016) 